\title{
Water Consumption from Hydroelectricity in the United States
}

Emily A. Grubert*, Emmett Interdisciplinary Program in Environment and Resources, Stanford University, Stanford, CA, USA.

\begin{abstract}
Understanding the relationship between water and energy systems is important for effective management of both resources. Improved data availability has made more comprehensive modeling of hydropower and its water use possible, even as droughts and climate change have made questions about reservoir evaporation responsiveness more timely. This work makes three main contributions: first, it presents national and regional estimates of gross evaporation and evaporation net of evapotranspiration from local land cover ("net evaporation") for U.S. hydroelectricity, arguing that net evaporation is more consistent with other measures of energyrelated water intensity; second, it introduces and validates a method for estimating system-wide evaporation based on primary purpose allocation that reduces data requirements by two orders of magnitude; and third, it makes available for public use a full Penman-Monteith model with multiple built-in sensitivity analyses. Based on this model, the U.S. hydropower system consumes an estimated average of $1.7 \mathrm{~m}^{3}$ of net freshwater per GJ electricity produced $\left(11 \mathrm{~m}^{3} / \mathrm{GJ}\right.$ gross).
\end{abstract}

Keywords water; energy; hydroelectricity; net evaporation; allocation; $k$-means clustering

*Corresponding author: E. A. Grubert, Emmett Interdisciplinary Program in Environment and Resources, Stanford University, 473 Via Ortega Ste 226, Stanford, CA 94305; email: gruberte@stanford.edu 


\section{Introduction}

Water and energy are both critical resources for human life, and modern practices have contributed to interconnections between water and energy systems. Energy is used to move, treat, and condition water, and water is used to access, process, and convert energy. Cooling systems at energy conversion facilities like power plants and refineries comprise one of the largest categories of freshwater withdrawal in the United States, at 38\% (tied with irrigation, also at 38\%) (Maupin et al., 2014). Understanding the water intensity of fuel life cycles, such as during resource extraction or processing, is increasingly important as water intensity effects on energy system management grow (e.g. Jornada and Leon, 2016; Koch and Vögele, 2009; Macknick et al., 2015; Sanders, 2014; Stillwell et al., 2011; Wolfe et al., 2009).

One of the clearest examples of energy-related water use is hydroelectricity, or electricity generated by water flowing through a turbine. While it is clear that water is being "used" for hydroelectricity, that use is qualitatively different from water use in other major energy systems: consumption is associated with evaporation and unrecoverable seepage from reservoirs behind dams rather than with extractive and cooling operations. Independent reservoir evaporation estimates are well represented in the literature (e.g. Gerbens-Leenes et al., 2009; Gleick, 1994; Herath et al., 2011; Mekonnen and Hoekstra, 2012; Pasqualetti and Kelley, 2008; Pfister et al., 2011; Torcellini et al., 2003), in part because evaporative consumption is thermodynamically driven and thus easier to calculate from physical principles than many other types of water use in energy systems. However, estimates vary so widely — perhaps because they are almost always based on samples rather than consistent populations of reservoirs - that they are not especially useful for comparison of hydropower's water intensity to that of other energy resources. Indeed, hydroelectricity is often excluded from comparative studies (e.g. Sanders, 2014; Elcock, 2010; 
Ruddell et al., 2014; Spang et al., 2014). Such exclusion can lead to important oversights: for example, decisions about removing, repowering, or altering storage patterns for roughly 750 single-purpose hydroelectric dams (out of 2,200 total U.S. hydroelectric facilities, USACE, 2013) could be affected by a better understanding of their water intensity relative to alternatives. Particularly as other low-carbon energy resources become more cost effective and more able to provide the types of ancillary services hydropower is valued for through e.g. batteries and power electronics, even existing hydroelectricity is not necessarily the most environmentally benign option. Thus, overcoming the problems of not having trustworthy estimates for hydroelectricity's water intensity or a practical method for allocating consumption to hydropower are important.

This study argues that, for the purpose of comparing hydroelectricity's water intensity to that of other energy resources, estimates can be improved with a usable, generalizable, and transparent method of assessing system-wide evaporative water consumption from hydroelectricity based on each reservoir's primary purpose and by considering net rather than gross evaporation. A cluster analysis-based method for making this estimate is demonstrated using the United States' entire population of hydroelectric dams, with national and regional estimates for both net and gross evaporation. This work thus demonstrates potential approaches to two major challenges in the hydropower and water-energy nexus literature: how to allocate environmental impacts of multipurpose reservoir infrastructure to derive general and representative estimates and how to estimate net evaporation from reservoirs.

\subsection{Allocation}

There is currently no accepted methodology for allocating impacts to multiple reservoir purposes (Bakken et al., 2013), and it is unlikely that a methodology appropriate for certain kinds 
of questions (e.g. "how much water does the U.S. hydroelectricity system consume through evaporation?") is appropriate for all others (e.g. "how should I manage this particular reservoir?"). This work proposes primary purpose-based allocation for a system-wide intensity estimate. This proposal is based on the idea that a reservoir's primary purpose is a reasonable proxy for the primary driver of its construction and evaporative impacts. Primary purpose-based allocation is coarse but unambiguous, as an internally consistent and comprehensive database of primary purpose exists for U.S. dams: the United States Army Corps of Engineers' (USACE) National Inventory of Dams (NID). While the ability to characterize individual dams at high resolution is lost with such an allocation procedure, system-wide (e.g. regional or national) dynamics are reasonably well represented assuming that all reservoirs are included in the analysis.

One major reason for seeking a system-level allocation method is that properly allocating across purposes at a particular site imposes a substantial data burden. Bakken et al. suggest that allocating environmental impacts to uses at a multipurpose reservoir be based on volumetric relationships derived from a single data source and verified by a site visit (2015). Given that over 2,200 facilities produce hydroelectricity in the U.S. (USACE, 2013), such internal consistency and detailed physical review is not practical, particularly given that such single data sources on the various outputs of a dam often do not exist. Where these data sources do exist, they often rely on value judgments that are not consistent across facilities. Such reservoir-level data and locallygrounded valuation can be immensely valuable for local use, but consistent system-wide conclusions are very difficult to draw from these studies. Additionally, those reservoirs for which sufficient information does exist tend not to be representative of the overall system, as larger or more controversial facilities are more likely to be well studied. 
Part of the issue with reservoir-based allocation is that a multipurpose dam's products are not typically discrete, well-defined outputs: "coproducts" to which environmental impacts are assigned are often highly subjective and site-specific, such as recreational values, ecosystem services, and relatively inelastic outcomes like flood control and navigability. Further, the marginal contribution of a cubic meter of water storage to provision of these services is difficult to ascertain. This fact makes it challenging to use well-established recommendations for environmental impact allocation, such as those in Life Cycle Assessment (LCA). LCA recommends that allocation across products be avoided if at all possible, but if necessary, that it proceed first based on physical relationships (e.g. the mass of output in each product), and then, only if necessary, based on economic or other relationships (ISO, 2006). For dams, economic allocation in particular suffers from the problem that some of the more economically significant activities associated with a reservoir might be entirely incidental to the original rationale for construction. For example, recreational and ecosystem service values associated with a reservoir might dominate present day economic benefits, but on their own, these uses would not have resulted in the construction of the reservoir and are thus dubiously responsible for evaporation. Economic allocation is found in the literature (e.g. Zhao and Liu, 2015; Liu et al., 2015), but it is often applied to dams selected based on data availability rather than true representativeness, and it usually does not capture all positive and negative economic effects of a given reservoir due to the issues of intangible valuation and nonlinear value of marginal volumes of water described above. Even when a consistent database of economic values is available, economic valuations can be highly contested: deep ethical concerns often accompany efforts to assign monetary value to various impacts of dams, particularly since many do not account for negative effects of e.g. inundation, habitat losses, and downstream effects in those valuations. 
To avoid problems like those described above, allocations of environmental burden are often made very conservatively, for example by assigning all impacts to a single use regardless of the importance of that use in overall dam operations. Many works overestimate the water impact of hydropower by assigning all evaporation from reservoirs associated with any hydroelectricity production to hydroelectricity (e.g. Herath et al., 2011; Mekonnen and Hoekstra, 2012; Pfister et al., 2011; Torcellini et al., 2003; Gleick, 1992; Macknick et al., 2012, via citation). Considering the distribution of primary purposes in a system rather than evaluating impacts at the individual dam level can add nuance without adding large amounts of subjectivity or imposing unrealistically large data burdens.

\subsection{Net versus gross evaporation}

The nature of evapotranspirative consumption presents a question about whether gross evaporation or evaporation net of that by local land cover is more appropriate. One important position supporting the use of net evaporation is found in the recently published ISO 14046 standard on water footprinting, which notes that "Change in evaporation caused by land-use change is considered water consumption (e.g. reservoir)" (ISO, 2014). Net evaporation reflects the fact that landcover evapotranspires water before inundation by a reservoir, and the evaporation associated with the open water surface of the reservoir might be higher or lower than the original evapotranspiration. Depending on transpiration rates of the original vegetation, then, net evaporation can be positive or negative. While gross evaporation from the reservoir surface is important for analyses like regional water balances, the net evaporation - that is, the change induced by inundation — more accurately describes human appropriation of water for dam-related uses. 
Despite recent movement toward net evaporation, net evaporation estimates for hydropower remain unusual in the literature, particularly at the system level. Herath et al. show that considering prior vegetation is important for consumption estimates (2011); Torcellini et al. consider evaporation from the original river surface area but do not include evapotranspiration from inundated local vegetation (2003). Strachan et al. provide important empirical grounding with a recent, measurement-based study of net evaporation from a reservoir in the Canadian boreal forest (2016). This work contributes both gross and net estimates for hydroelectricityrelated water consumption in the U.S.

\section{Methods}

\subsection{Data Sources and Data Collection}

This analysis relies on four major types of data: reservoir characteristics, climatic data, electricity generation data, and land cover data. This section describes the data sources used for each (instructions for accessing the data and models are found in Text S1.1).

\subsubsection{Reservoir characteristics Dam data are taken from the 2013 edition of the NID} (USACE, 2013). Attributes collected from the NID include dam names, identification numbers, locations (as decimal latitude and longitude, as well as county and state), associated reservoir surface area, associated reservoir normal storage, primary facility purpose, and all listed facility purposes. Reservoir depths associated with dams with a primary purpose of hydroelectricity are calculated based on NID data as reservoir normal storage in acre-feet divided by reservoir surface area in acres (note that in the NID, "normal storage" includes dead storage and "surface area" is defined as surface area at normal retention area (NOAA, 2015), so this method appropriately estimates average reservoir depth). 
2.1.2 Climatic data Long-term average climatic data are taken from the National Climatic Data Center (NCDC) (Applequist et al., 2011) and insolation data from the National Renewable Energy Laboratory (NREL, 2012). More detail about these datasets and the approximation used to derive wet bulb temperature can be found in Text S1.2.

2.1.3 Electricity generation data Hydroelectricity data are collected from the Energy Information Administration (EIA)'s Form 923 (EIA, 2015). Generation used in this analysis is the 2010-2014 average. Generators are associated to dams by means of an approximate matching system based on longitude and latitude: as dams and powerhouses are not always colocated, the match is inexact. The process is described in Text S1.3.

2.1.4 Land cover data Land cover data are collected from the United States Geological Survey (USGS)' National Land Cover Database (NLCD) 2011 (Homer et al., 2015). Land cover characteristics are assigned to locations based on visual inspection of maps: specifically, the map of centroids and associated facilities was overlaid with the NLCD and evaluated for the most common land cover at facility locations (Figure 1). Where land cover is ambiguous, for example due to high diversity in a small area, the land cover with the lowest evapotranspiration coefficient is selected so as to conservatively overestimate the net evaporation potentially attributable to hydropower. No attempt is made to assess what the pre-reservoir land cover might have been in each region and extrapolate those conditions to present-day, even though the presence of reservoirs likely influences local land use. For example, centroid 8 (Idaho and nearby states) shows a wide band of crop cover surrounding the areas hosting reservoirs, which is likely due to the provision of irrigation water from Snake River reservoirs. For details of how data are prepared and cleaned for analysis, including how duplicates and natural lakes are removed, see Text S1.4. 


\subsection{Allocation}

One of the biggest challenges in assessing the water intensity of hydropower is defining and using an allocation metric that appropriately accounts for the multipurpose nature of dam and reservoir infrastructure. This work considers six allocation methods, including two typical in the energy-water nexus literature (assigning all or no reservoir evaporation to hydroelectricity), two based on economic values, and two based on reservoir purpose. The allocation method that best meets this work's goals of usability, generalizability, and transparency, allocation based on each reservoir's listed primary purpose, is selected as the preferred method and is described below. The other five allocation procedures considered are described in detail in Text S1.5.

For allocation based on each reservoir's primary purpose, evaporation from a given reservoir is assigned to the reservoir's NID-designated primary purpose, producing an overall estimate of

$$
\text { water intensity }=\frac{\sum_{\text {primary purpose }=\text { hydroelectricity evaporation }}}{\sum_{\text {all hydro generators }} \text { generation }}(\text { Equation } 1) .
$$

Since the water intensity is reported for a system of dams rather than for a single dam, this level of aggregation reflects the multipurpose nature of the system but not individual facilities. Thus, this method is well suited to large-scale investigation.

In order to capture the full population of hydroelectric facilities, analysis proceeds by narrowing the U.S. population of over 70,000 dams for all purposes to the subpopulation of dams that produce hydroelectricity (about 2,200 dams) (USACE, 2013), then cross-referencing with the list of all hydroelectric generators to ensure that generators without reservoirs are captured (EIA, 2015). About one third of the 2,200 U.S. hydroelectricity-producing dams (756) are designated as hydroelectricity-only in the NID. Another third are multipurpose dams with 
hydroelectricity as their primary purpose, for a total of 1,563 dams with primary purpose $=$ hydroelectricity. These dams account for $60 \%$ of hydroelectric generation and $45 \%$ of hydroelectric-associated reservoir surface area: remaining generation is from dams with primary purposes other than hydroelectricity. Evaporation from these 1,563 dams is allocated to hydroelectricity and divided by $100 \%$ of U.S. hydroelectric generation to calculate systemic water intensity (Equation 1), just as evaporation from reservoirs with other primary purposes (like flood control) is assigned to those other purposes for an internally consistent, systemic assessment of water intensity across the many purposes for which dams and reservoirs are built and operated.

While this allocation method is systemically accurate given its breadth, it is not appropriate for high resolution investigation of individual dams: for example, primary purposebased allocation to flood control is not particularly useful for management at Grand Coulee Dam, the U.S.' biggest power plant, or at Buford Dam, a major source of Atlanta's drinking water. However, on the whole, such system-based allocation adds a new perspective to a literature that typically relies on extrapolating results from studies of nonrepresentative samples of dams and reservoirs. Capacity, generation, number of units, and reservoir surface area for both groups of powered dams, as well as the remaining hydroelectric facilities not associated with dams or with missing NID data, are presented in the Supporting Information (SI) Table S1.

\subsection{Evaporation Modeling}

This work models evaporation from reservoirs using the Penman-Monteith equation (which includes heat storage in reservoirs), described in detail by Mekonnen and Hoekstra (2011). The complete Excel-based models are available online (links in Text S1.1). The raw 
Penman-Monteith result, using a depth-dependent evaporation coefficient for the open water surfaces of the reservoirs, is the gross evaporation estimate. Net evaporation is calculated by subtracting the estimated evapotranspirative water consumption of pre-inundation landcover, modeled by applying evapotranspiration coefficients (Natural Capital Project, 2012) for the land cover in the region surrounding reservoirs of interest to the reservoir surface area. While this estimate does not account for pre-reservoir river area, in most cases where the evapotranspiration coefficient of the land cover is significantly lower than that of open water, pre-reservoir river surface area is a very low proportion of reservoir surface area (e.g. Torcellini et al., 2003). Hydroelectric water consumption is assumed to be freshwater in all cases.

\subsection{Generating Proxies via k-means Clusters}

Given the high data requirements for each reservoir surface analyzed (a total of 78 variables when monthly averages are used: see Table S2), this analysis condenses the data burden by using clustering to generate proxy analytical locations. Specifically, reservoirs in a given sample are weighted by surface area (due to its direct linear effect on evaporation) and $k$ means clustered based on latitude and longitude of the reservoirs' associated dams. Then, climatic data are collected for each cluster centroid rather than each reservoir. In the case where $k=20$, as used in this analysis, this clustering reduces the total input data requirement to about 1,600 unique inputs from the 122,000 unique inputs that would be required to analyze the system reservoir-by-reservoir (this does not include any data required for more detailed allocation). The $k$ value of 20 was chosen based on tests for $k=[5,40]$ based on its position past the elbow of the within-class variance versus $k$ plot and its relatively better representation of U.S. climate 
variability than lower $k$, based on comparison of centroid location with pan evaporation charts (Figure S1).

Centroid-associated climatic data are applied to a proxy reservoir with the average surface area and average depth of the reservoirs in each cluster to calculate evaporation from the proxy reservoir, then multiplied by the number of reservoirs to calculate evaporation from the full reservoir surface area in each centroid. Essentially, evaporation by centroid is calculated as the sum of evaporation from some number of identical lakes (each with the average properties of the lakes in the centroid) located at the centroid location. Table S3 summarizes centroid characteristics. Additional detail on $k$-means analysis and data assignment can be found in Figure 1, Figure S1, and Text S1.6.

\section{Results and Discussion}

This analysis finds that based on a primary purpose-based allocation and long-term average reservoir, climate, and electricity generation data, U.S. hydroelectricity consumes a gross estimated $11 \mathrm{~m}^{3} / \mathrm{GJ}\left(38 \mathrm{~m}^{3} / \mathrm{MWh}\right)$ from reservoir evaporation. Accounting for land cover in the areas where reservoirs are located, net consumption is estimated at $1.7 \mathrm{~m}^{3} / \mathrm{GJ}(6.0$ $\mathrm{m}^{3} / \mathrm{MWh}$ ). This net consumption estimate implies that mean U.S. hydroelectric water consumption per unit of energy produced is well above that of other electricity fuel cycles, at about 2.5 times median estimates for coal and about 8 times median estimates for natural gas combined cycle systems (Macknick et al., 2012), but it is much closer than previous estimates indicating at least an order of magnitude difference. In regions like the Pacific Northwest, where hydropower is a major portion of the electricity system, net water consumption is effectively 0 . 
Regional consumption is discussed in Text S2.1 and is summarized by centroid in Figure 2 and Table S4.

\subsection{U.S. Consumptive Water Intensity of Hydropower}

This work finds that US hydroelectricity is responsible for about $1.7 \mathrm{~m}^{3} / \mathrm{GJ}$ of net evaporation-based freshwater consumption based on long-term averages for climatic data, generation data, and reservoir characteristics. Since many of the US' hydroelectricity-purposed reservoirs are located in areas where relatively water intensive land covers like crops or forests are dominant, the net evaporation is significantly lower than the gross estimate of $11 \mathrm{~m}^{3} / \mathrm{GJ}$ (net and gross evaporation are further discussed in Text S2.2). Text S2.3 describes another potential driver of hydroelectricity-related water consumption, nonrecoverable seepage, and explains why it is unlikely to be as important as evaporation.

While few net evaporation estimates exist in the literature, the gross estimate can be compared to previously published values to check for consistency. The gross estimate of 11 $\mathrm{m}^{3} / \mathrm{GJ}$ made here falls between other widely cited US-based estimates of $4.7 \mathrm{~m}^{3} / \mathrm{GJ}$ (Gleick, 1994; cited in Macknick et al., 2012 and Fthenakis and Kim, 2010) and $17 \mathrm{~m}^{3} / \mathrm{GJ}$ (Torcellini et al., 2003), suggesting that it is reasonable. While the data set and analytical method used to derive the $4.7 \mathrm{~m}^{3} / \mathrm{GJ}$ estimate are not clearly defined, the $17 \mathrm{~m}^{3} / \mathrm{GJ}$ estimate is based on free water surface (FWS) evaporation from the reservoirs associated with 1999's 120 top U.S. hydropower-producing dams, while this estimate is based on clusters comprising all U.S. dams with primary purpose $=$ hydroelectricity .

As discussed throughout this paper, this analysis allocates reservoir evaporation across dam uses at a system level by assigning evaporation from dams primarily for hydroelectricity to 
the entire hydroelectric generation of the U.S., unlike many analyses that only consider the generation from facilities analyzed for evaporation. If this analysis were to calculate water intensity looking only at the facilities with hydroelectricity as a primary purpose for both evaporation and generation, net evaporation would be estimated at $2.8 \mathrm{~m}^{3} / \mathrm{GJ}$ and gross at 18.1 $\mathrm{m}^{3} / \mathrm{GJ}$. This estimate is nearly twice the whole-system estimate and is similar to the Torcellini et al. estimate (2003). Thus, capturing the hydroelectricity from those dams that are primarily serving other purposes for an overall system intensity estimate is very important, nearly halving the estimated water intensity of the system. Based on this analysis, this work recommends the use of as comprehensive a sample as possible both for generators and reservoirs. This framing improves representativeness of the output in addition to capturing two important facility populations that are easy to exclude when noncomprehensive samples are used: reservoirs built for hydroelectricity that produce very little power but continue to lose water and facilities that produce hydroelectricity without an impoundment.

\subsection{Limitations and Recommended Use of Results}

Use of the results of this analysis for applications requiring high resolution data, particularly for a single watershed or dam, is not advised. While the models accompanying this paper are available for use and adaptation to settings at any scale and any region appropriate for Penman-Monteith evaluation, the U.S. results presented here are intended to provide high-level national and regional data for use as a starting point for decision making to identify targets for higher resolution study, and in particular to demonstrate the effects of considering net versus gross evaporation. This study uses highly aggregated data and relatively nonspecific information to estimate evaporation and is not a substitute for detailed analysis of a particular water 
management system for high resolution decision making. For example, climatic data from a station within 100 miles of an aggregated reservoir centroid was considered adequate for this work, and evapotranspiration coefficients are general estimates rather than detailed measurements as used by Strachan et al. (2016). Similarly, a coarse approximation of wet bulb temperature based on dew point temperature was used, which creates errors of up to $10 \%$ for summertime estimates in warm regions. Additionally, some data characteristics are not explicit, for example the height of wind speed measurement. Results of sensitivity analyses and use of the models to evaluate possible impacts from climate change and drought are presented in Text S2.4: the most sensitive parameters are insolation, electricity generation, and reservoir area, discussed in detail in the SI.

\subsection{Effects of Allocation Metric on Water Intensity Estimate}

Allocation across multiple reservoir uses remains challenging for analysts. This work argues that system-level allocation of evaporation based on a reservoir's primary purpose is a useful and practical allocation scheme for large investigations of water intensity. Figure 3 presents the results of a rough estimate of how the water intensity results presented in this study would change under different allocation regimes described in Text S1.5. The most common allocation schemes in the energy-water literature, either assigning all or no evaporation associated with a powered dam to hydroelectricity, result in estimates that are double that based on primary purpose allocation and 0 , respectively. Allocating impacts based on equal weighting of all purposes (that is, if a reservoir is designated for flood control and hydroelectricity, each purpose is assigned half the burden) reduces the estimated water intensity of hydroelectricity, 
while the effect of economic allocation on the water intensity of hydroelectricity varies depending on assumptions.

A very important insight from Figure 3 is that estimated water intensity of hydroelectricity is relatively insensitive to choice of literature-supported method for allocation of environmental impacts from powered dams to hydroelectricity (between about a third and half of the impacts in all cases where multi-use allocation is attempted), but water intensity of other reservoir uses is far more sensitive. In particular, economic approaches tend to undervalue systemic or rare benefits like navigation and protection from major floods, in part due to challenges associated with assigning marginal value of those services to a given volume of water. Thus, even though a primary purpose allocation of powered dams shows that many are intended as flood control dams, that use receives very little attention from economic valuation mechanisms evaluated here. Another caution about using economic allocation, particularly based on marginal value, is that not all uses can support the same volumes of use: while fishing might be particularly valuable per marginal $\mathrm{m}^{3}$ of water, many fewer $\mathrm{m}^{3}$ of water will actually deliver this economic benefit relative to a large-volume user like hydroelectricity or irrigation.

\section{Acknowledgments}

This material is based upon work supported by the National Science Foundation Graduate Research Fellowship Program under Grant No. DGE-114747. Any opinions, findings, and conclusions or recommendations expressed in this material are those of the author and do not necessarily reflect the views of the National Science Foundation. 
Thank you to R. Phillips for suggestions on land cover and reservoir porosity and to several

anonymous reviewers for their very helpful comments.

\section{References}

Applequist, S.; Arguez, A.; Durre, I.; Squires, M.; Vose, R.; Yin, X. Computational Procedures for the 1981-2010 Normals: Hourly Products. National Oceanic and Atmospheric Administration: 2011. ftp://ftp.ncdc.noaa.gov/pub/data/normals/1981-

2010/documentation/hourly-methodology.pdf

Bakken, T. H.; Killingtveit, å.; Engeland, K.; Alfredsen, K.; Harby, A. Water consumption from hydropower plants--review of published estimates and an assessment of the concept. Hydrology and Earth System Sciences 2013, 17 (10), 3983-4000.

Bakken, T. H.; Kjosavik, F.; Killingtveit, å.; Alfredsen, K. Are Reservoirs Water Consumers or Water Collectors? Reflections on the Water Footprint Concept Applied on Reservoirs. Water Resources Management 2015, 29 (14), 4919-4926.

Elcock, D. Future US Water Consumption: The Role of Energy Production1. JAWRA Journal of the American Water Resources Association 2010, 46 (3), 447-460.

Energy Information Administration (2015), EIA-923 Electric Power Generation and Fuel Consumption, Stocks, and Receipts Monthly Time Series Data, 2014 Final Release, http://www.eia.gov/electricity/data/eia923/.

Fthenakis, V.; Kim, H. C. Life-cycle uses of water in U.S. electricity generation. Renewable and Sustainable Energy Reviews 2010, 14 (7), 2039-2048.

Gerbens-Leenes, P. W.; Hoekstra, A. Y.; van der Meer, T. The water footprint of energy from biomass: A quantitative assessment and consequences of an increasing share of bio-energy in energy supply. Ecological Economics 2009, 68 (4), 1052-1060.

Gleick, P. H. Environmental consequences of hydroelectric development: The role of facility size and type. Energy 1992, 17 (8), 735-747.

Gleick, P. H. Water and Energy. Annual Review of Energy and the Environment 1994, 19 (1), 267-299.

Herath, I.; Deurer, M.; Horne, D.; Singh, R.; Clothier, B. The water footprint of hydroelectricity: a methodological comparison from a case study in New Zealand. Journal of Cleaner Production 2011, 19 (14), 1582-1589.

Homer, C.G.; Dewitz, J.A.; Yang, L.; Jin, S.; Danielson, P.; Xian, G.; Coulston, J.; Herold, N.D.; Wickham, J.D.; Megown, K. Completion of the 2011 National Land Cover Database for the conterminous United States-Representing a decade of land cover change information. Photogramm. Eng. Remote Sens. 2015, 81(5), 345-354.

ISO 14040:2006 - Environmental management -- Life cycle assessment -- Principles and framework, 2006. Available from: http://www.iso.org/iso/catalogue_detail?csnumber=37456

ISO 14046:2014 - Environmental management -- Water footprint -- Principles, requirements and guidelines, 2014. Available from: http://www.iso.org/iso/catalogue_detail?csnumber=43263

Jornada, D.; Leon, V. J. Robustness methodology to aid multiobjective decision making in the electricity generation capacity expansion problem to minimize cost and water withdrawal. Applied Energy 2016, 162, 1089-1108. 
Koch, H.; Vögele, S. Dynamic modelling of water demand, water availability and adaptation strategies for power plants to global change. Ecological Economics 2009, 68 (7), 2031-2039.

Liu, J.; Zhao, D.; Gerbens-Leenes, P.; Guan, D. "China's Rising Hydropower Demand Challenges Water Sector.” Scientific Reports 2015. doi:10.1038/srep11446.

Macknick, J.; Cohen, S. M.; Newmark, R.; Martinez, A.; Sullivan, S.; Tidwell, V. Water constraints in an electric sector capacity expansion model. NREL/TP-6A20-64270. National Renewable Energy Laboratory: Golden, CO, 2015.

Macknick, J.; Newmark, R.; Heath, G.; Hallett, K. C. Operational water consumption and withdrawal factors for electricity generating technologies: a review of existing literature. Environ. Res. Lett. 2012, 7 (4), 045802.

Maupin, M.A.; Kenny, J.F.; Hutson, S.S; Lovelace, K.K.; Barber, N.L.; Linsey K.S. Estimated use of water in the United States in 2010: U.S. Geological Survey Circular 1405: Reston, VA, 2014; http://pubs.usgs.gov/circ/1405/.

Mekonnen, M. M.; Hoekstra, A. Y. The blue water footprint of electricity from hydropower. Hydrol. Earth Syst. Sci. 2012, 16 (1), 179-187.

Mekonnen, M. M.; Hoekstra, A. Y. The water footprint of electricity from hydropower. 2011.

National Oceanic and Atmospheric Administration (2015), NID Documentation, http://www.nws.noaa.gov/om/water/WFO_support/documentation/damcat_dict.shtml.

National Renewable Energy Laboratory. PV Solar Radiation (10 km)—Static Maps (1998 to 2005 data). 2012. http://www.nrel.gov/gis/solar.html.

Natural Capital Project. Water Yield: Reservoir Hydropower Production - InVEST 2.6.0 documentation. 2012. Available from: http://data.naturalcapitalproject.org/investreleases/documentation/2_6_0/reservoirhydropowerproduction.html

Pasqualetti, M. J.; Kelley, S. The Water Costs of Electricity in Arizona; Arizona Water Institute, 2008; p 12.

Pfister, S.; Saner, D.; Koehler, A. The environmental relevance of freshwater consumption in global power production. Int J Life Cycle Assess 2011, 16 (6), 580-591.

Ruddell, B. L.; Adams, E. A.; Rushforth, R.; Tidwell, V. C. Embedded resource accounting for coupled natural-human systems: An application to water resource impacts of the western U.S. electrical energy trade. Water Resour. Res. 2014, 50 (10), 7957-7972.

Sanders, K. T. Utilizing a Unit Commitment and Dispatch Model to Temporally Resolve Water Use Data in the Western United States' Power Sector; American Society of Civil Engineers, 2014; pp 994-1000.

Spang, E. S.; Moomaw, W. R.; Gallagher, K. S.; Kirshen, P. H.; Marks, D. H. The water consumption of energy production: an international comparison. Environ. Res. Lett. 2014, 9 (10), 105002.

Stillwell, A. S.; Clayton, M. E.; Webber, M. E. Technical analysis of a river basin-based model of advanced power plant cooling technologies for mitigating water management challenges. Environ. Res. Lett. 2011, 6 (3), 034015.

Strachan, I. B.; Tremblay, A.; Pelletier, L.; Tardif, S.; Turpin, C.; Nugent, K. A. Does the creation of a boreal hydroelectric reservoir result in a net change in evaporation? J. Hydrol. 2016.

Torcellini, P. A.; Long, N.; Judkoff, R. Consumptive water use for US power production; National Renewable Energy Laboratory: Golden, CO, 2003.

United States Army Corps of Engineers. CorpsMap: The National Inventory of Dams (NID), 2013. http://nid.usace.army.mil/cm_apex/f?p=838:12. 
Wolfe, J. R.; Goldstein, R. A.; Maulbetsch, J. S.; McGowin, C. R. An Electric Power Industry Perspective on Water Use Efficiency. Journal of Contemporary Water Research \& Education 2009, 143 (1), 30-34.

Zhao, D.; Liu, J. A new approach to assessing the water footprint of hydroelectric power based on allocation of water footprints among reservoir ecosystem services. Physics and Chemistry of the Earth, Parts A/B/C 2015, 79-82, 40-46. 
Figures

Figure 1. $\boldsymbol{k}=\mathbf{2 0}$ centroids for $\mathbf{4 8}$ contiguous U.S. states

Panel 1a. All facilities associated to each of $k=20$ centroids

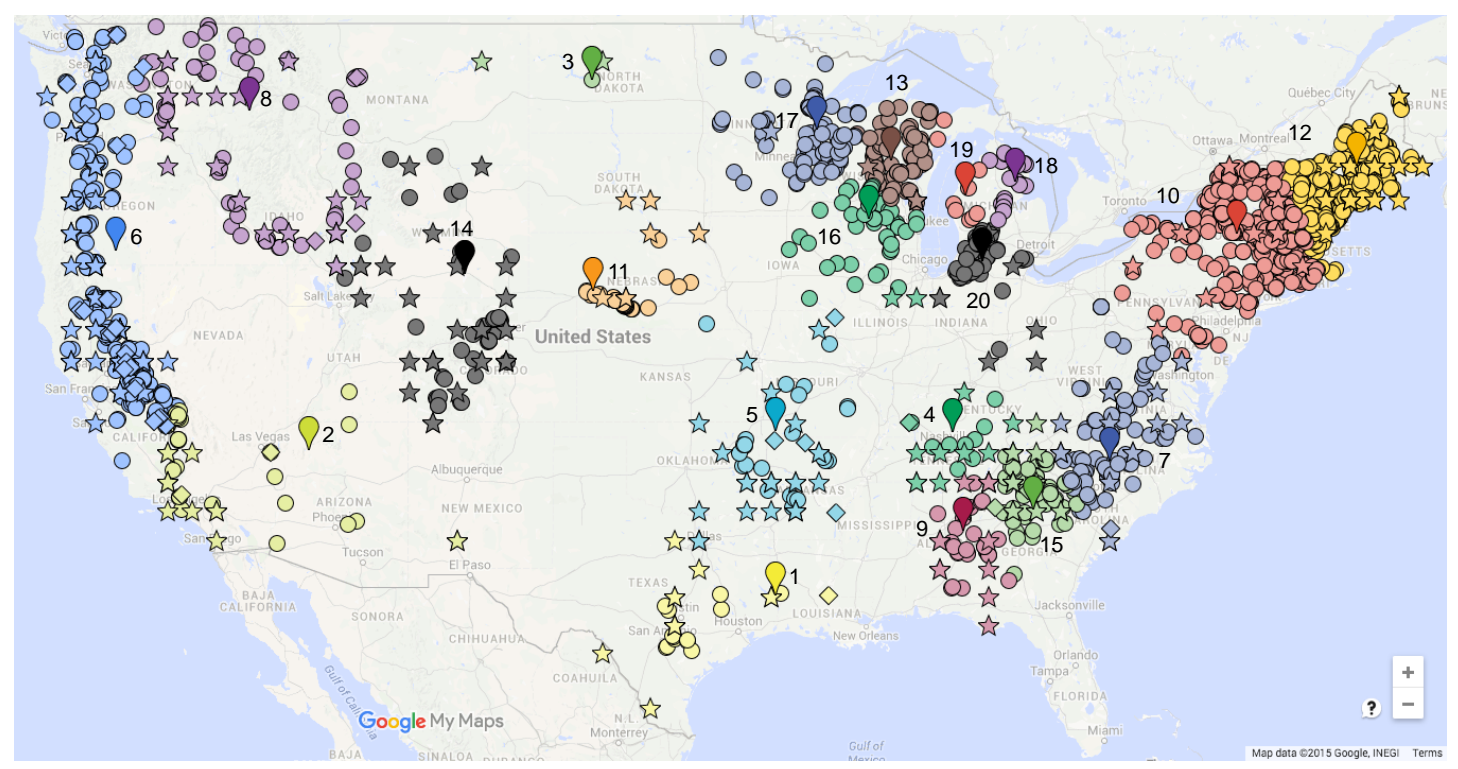

Panel 1b. Dams with primary purpose $=$ hydroelectricity with regional land cover

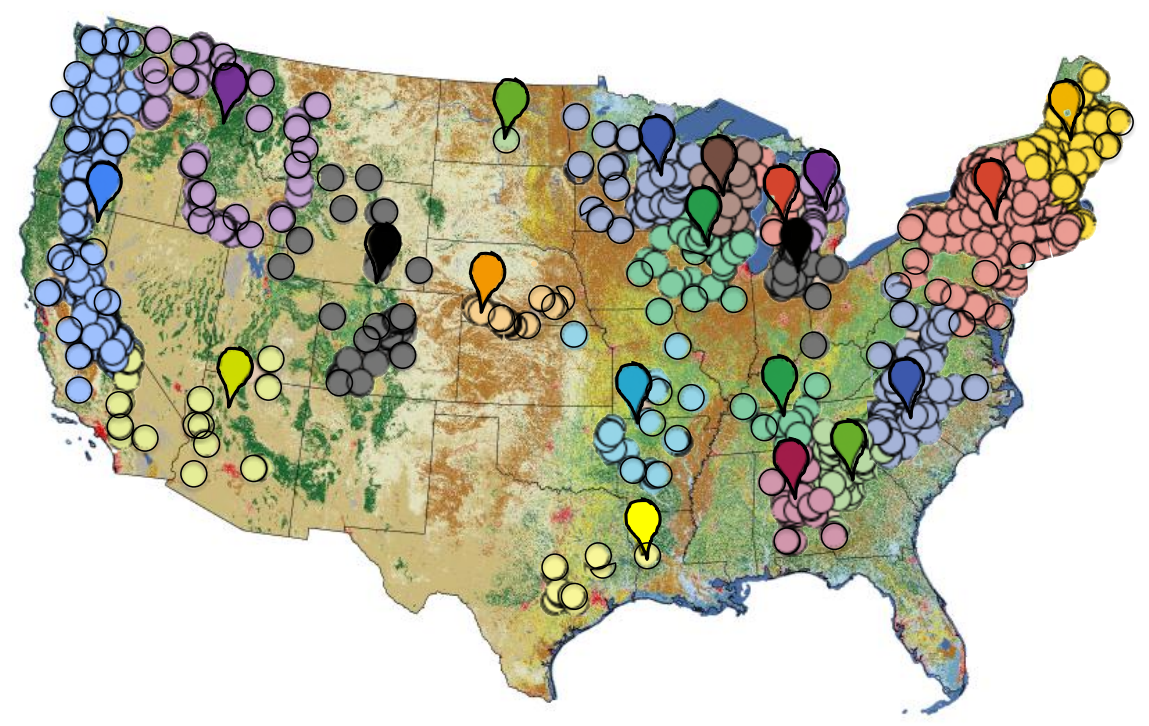


Figure 2. Estimated evaporative consumption from hydroelectricity by region $\left(\mathrm{m}^{3} / \mathbf{G J}\right)$

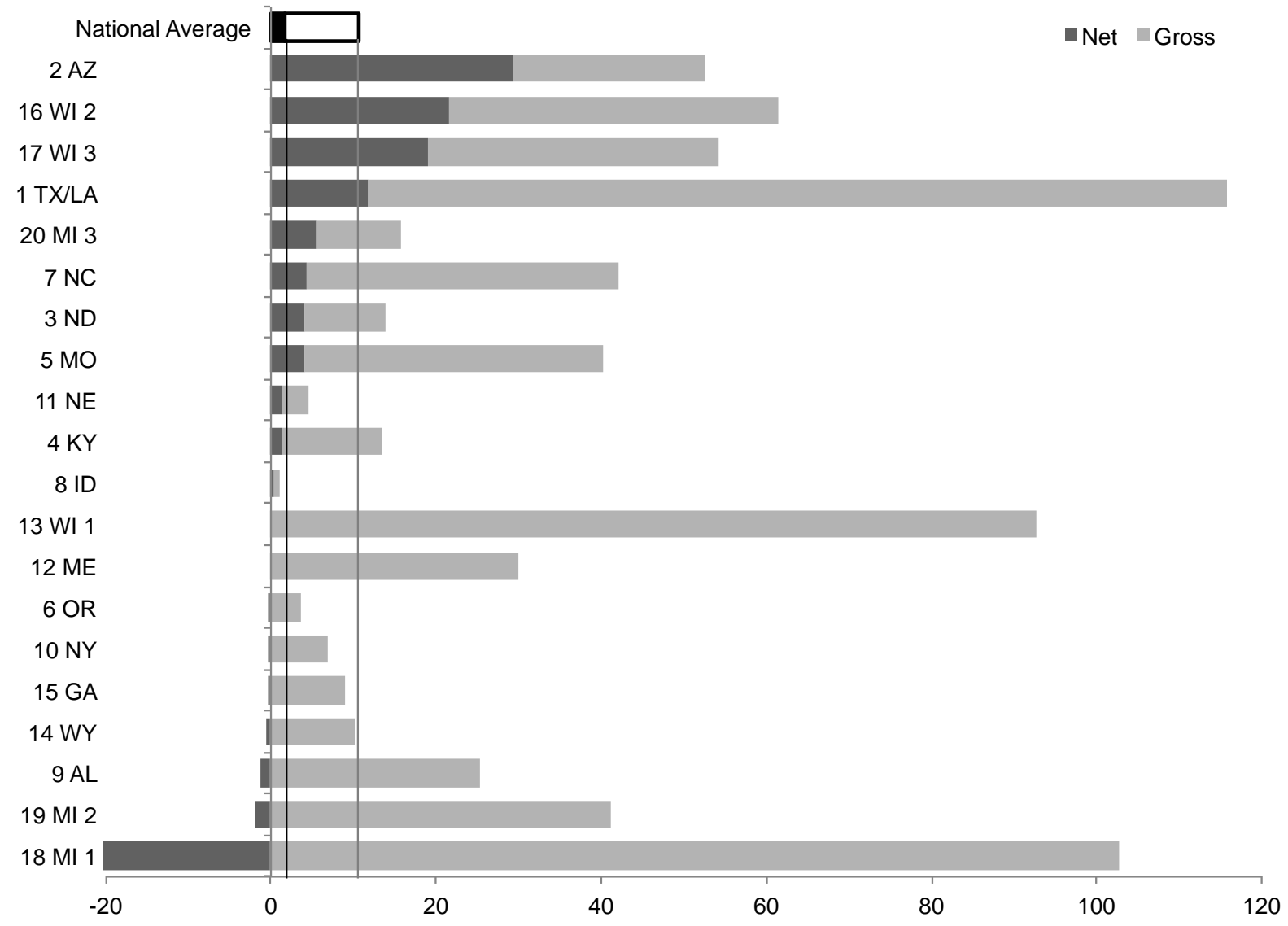


Figure 3. Effect of allocation metric on estimated water intensity of hydropower

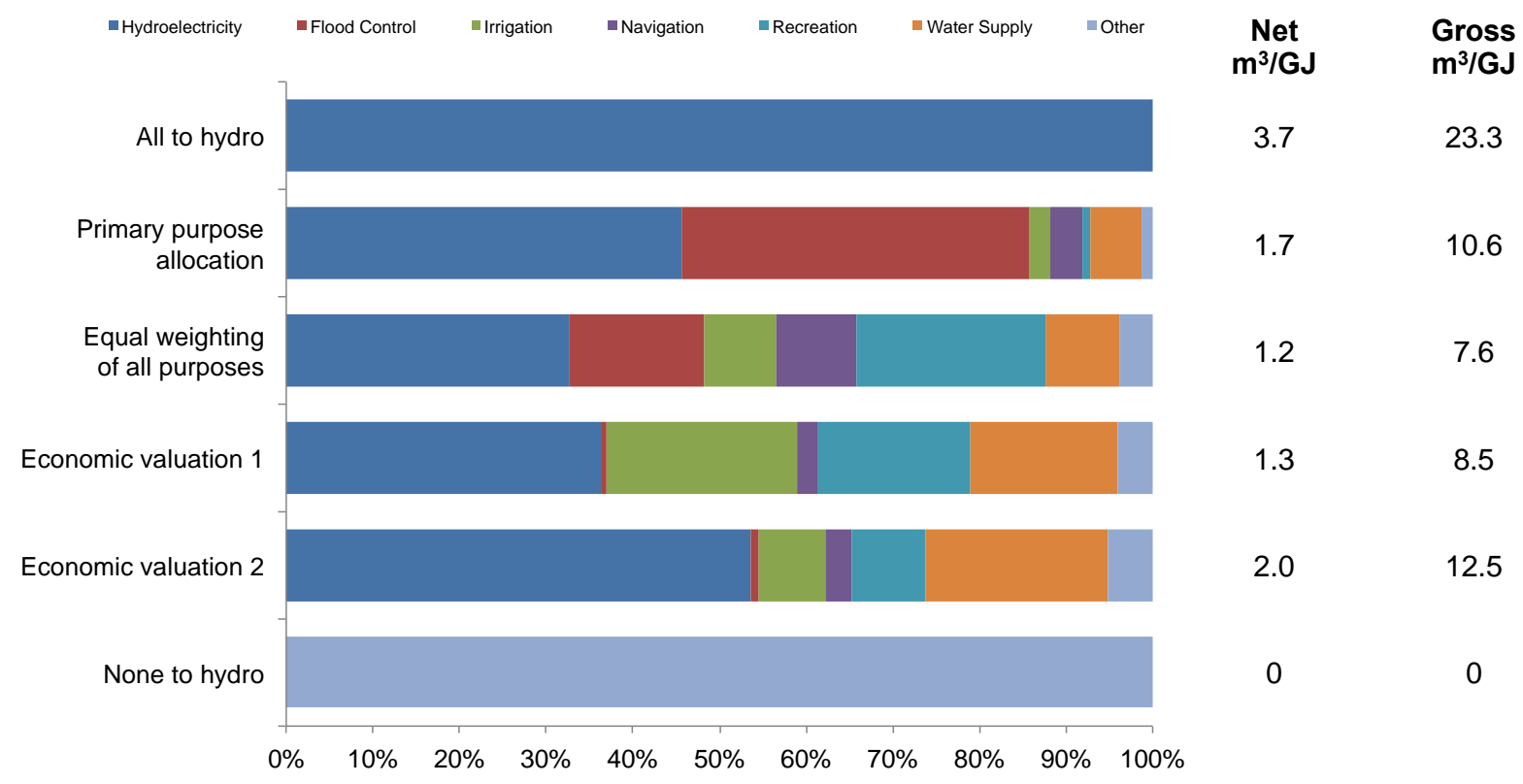




\section{Figure Captions}

Figure 1 Caption. (a) $20 k$-means centroids are used to describe the population of hydropower facilities in the contiguous 48 United States. Centroids are generated based on dams with primary purpose $=$ hydroelectricity based on reservoir surface area weighting. These dams are denoted as circles. Stars designate dams that produce hydroelectricity but not as their primary purpose. Diamonds designate facilities greater than $50 \mathrm{MW}$ in capacity in the EIA hydropower generator database but not the NID. These latter categories are assigned to centroids based on longitude and latitude. Dams are color-coded by centroid, consistent across panels (a) and (b). Map data (C) 2015 Google, INEGI. Used under fair use permissions. (b) $k$-means centroids are assigned a local land cover using the National Land Cover Database based on the dominant land cover at the site of reservoirs. Only reservoirs with primary purpose $=$ hydropower are used in this assessment, as only evaporation from these is allocated to hydropower.

Figure 2 Caption. Southwestern reservoirs in scrublands described have the highest net evaporative consumption of all regions, followed by reservoirs with high area relative to their power production in cropped areas. Gross evapotranspiration is not predictive of net evapotranspiration. Bar titles give the centroid number and the state where the centroid is located.

Figure 3 Caption. Allocation of environmental burden across multiple uses of reservoirs is a challenging topic in hydropower assessment. The most common methods in the energy literature assign all or none of the burden to hydroelectricity: this study instead proposes allocating evaporation at a whole-system level to reservoirs for which hydroelectricity is the primary purpose. 